\title{
TRANSPLANTE HEPÁTICO NO BRASIL: SITUAÇÃO ATUAL
}

\author{
Brazil liver transplantation: current situation
}

\author{
Eduardo RAMOS, Júlio Cezar Uili COELHO
}

Serviço de Transplante Hepático do Hospital de Clínicas da Universidade Federal do Paraná, Curitiba, PR, Brasil

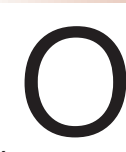

$s$ ava
perm
dos avanços da medicina na última década ermitiram melhora expressiva da sobrevida dos pacientes submetidos à transplante de órgãos. Atualmente o índice de sobrevida após esse procedimento nos Estados Unidos é de cerca de 85\% em um ano e de $70 \%$ em cinco anos. No Brasil, ainda não existem dados oficiais, mas publicações de alguns serviços indicam percentagens um pouco inferiores. O refinamento das técnicas cirúrgicas e a presença de drogas imunossupressoras potentes reduziram a rejeição significativamente. Entretanto a taxa de óbito ainda é grande entre as pessoas que estão na fila de espera por transplante hepático, devido à falta de um método adequado para manter o paciente com insuficiência hepática vivo, e ao baixo número de doadores de órgãos.

No Brasil, o número de doações de órgãos vem crescendo continuamente e significativamente por quase duas décadas. No ano de 2009 ocorreram 1.658 doadores falecidos (8,7 por milhão de pessoas), o que representou crescimento na doação de $26 \%$, devido principalmente ao aumento na taxa de efetivação de doação, que passou de $22 \%$ para $25,5 \%$. Concomitante houve aumento de $8 \%$ na notificação. Já em países desenvolvidos, o número de órgãos provenientes de doadores cadáver atingiu um ápice, sem nenhum crescimento significativo nos últimos anos. Isto se deve a vários fatores, sendo os principais: crescimento populacional pequeno, redução do número de acidentes automobilísticos fatais e aumento do número de indivíduos com doenças transmissíveis (HIV e hepatites virais). Em países desenvolvidos o número de doações é muito maior, alcançando 33 por milhão de pessoa na Espanha, país com o melhor sistema mundial de captação de órgãos. Estes dados sugerem que no Brasil, um país em franco desenvolvimento sócio-econômico, o número de transplantes tende a continuar a aumentar.

Em 2009 foram realizados 1322 transplantes hepáticos no nosso país, um aumento de $12,4 \%$ em relação a 2008. Este aumento contínuo deveu-se aos incentivos estabelecidos pelo governo federal, às campanhas de doação de órgãos realizadas pelas sociedades médicas e à melhor conscientização da população. Também de maneira positiva, as equipes transplantadoras e as centrais estaduais de transplante estão mais organizadas, e atualmente temos 50 equipes ativas realizando transplante hepático no Brasil.

Apesar deste aumento expressivo do número de transplantes nos últimos anos, um grande problema persiste: a má distribuição dos centros transplantadores no território nacional. Dos transplantes realizados em 2009, 51\% foram no Estado de São Paulo. Somente 11 estados brasileiros possuem centros de transplante. Este crescimento contínuo que veremos nesta década deve ser acompanhado por medidas que promovam melhorias na estrutura hospitalar e formação de equipes transplantadoras em todas as regiões do país, o que por sua vez, promoverá aumento na taxa de doação que se encontra atualmente desigual no território nacional.

Outra modificação importante de ser registrar com relação aos transplantes hepáticos é a tendência de indicações com doadores vivos (transplante intervivos). Após a realização do primeiro transplante hepático intervivos no mundo por Raia et al. na Universidade de São Paulo em 1989, houve aumento significativo no número desses transplantes no mundo até o ano de 2006. Desde então, o intervivos vem reduzindo gradualmente em quase todos os países, exceto nos asiáticos, aonde o número de doadores de órgãos cadavéricos é muito limitado. Esta redução se deve ao risco de complicações graves do doador e a introdução do sistema MELD (Model End Stage Liver Disease) para a lista de espera dos pacientes que aguardam transplante hepático. Visando distribuição mais justa e baseada em critérios de severidade da doença, e não apenas no tempo de espera em lista, o sistema MELD passou a ser utilizado no Brasil em 2006, fazendo com que pacientes mais graves tenham prioridade na lista de espera. No ano de 2005 foram realizados 192 transplantes intervivos no Brasil, seguido de queda contínua, e nos últimos dois anos foi de 121. Nos Estados Unidos e Europa a redução foi mais acentuada. Devido à limitação em se obter órgãos de doadores falecidos pediátricos, a indicação de transplantes de fígado intervivos em crianças permanece quase sempre a melhor opção.

Pelos dados apresentados, pode-se vislumbrar que nesta década que se inicia continuar-se-á testemunhando aumento progressivo no número de transplantes hepáticos. Nós, cirurgiões, devemos participar na conscientização da população e na divulgação dentro da nossa própria classe dos bons resultados obtidos nos últimos anos, tanto na doação quanto na sobrevida dos pacientes.

\section{REFERÊNCIAS}

1. Raia S, Nery JR, Mies S. Liver transplantation from live donors. Lancet. 1989 Aug 26;2(8661):497. 